\title{
Renewable energy regulation and structural breaks: An empirical analysis of Spanish electricity price volatility
}

\author{
Aitor Ciarreta $^{\mathrm{a}}$, Cristina Pizarro-Irizar ${ }^{\mathrm{b}}$, Ainhoa Zarraga ${ }^{\mathrm{c}}$ \\ ${ }^{a}$ University of the Basque Country, UPV/EHU, and BRiDGE. Department of Economic \\ Analysis II. Avda. Lehendakari Aguirre, 83. 48015 Bilbao, Spain. E-mail: \\ aitor.ciarreta@ehu.eus.Phone: +34946013823. \\ ${ }^{b}$ (Corresponding author) University of the Basque Country, UPV/EHU, and Basque Centre for \\ Climate Change, BC3. Department of Economic Analysis II. Avda. Lehendakari Aguirre, 83. \\ 48015 Bilbao, Spain. E-mail: mariacristina.pizarro@ehu.eus. Phone: +34946013770. \\ ${ }^{c}$ University of the Basque Country, UPV/EHU. Department of Applied Economics III. Avda. \\ Lehendakari Aguirre, 83.48015 Bilbao, Spain. E-mail: ainhoa.zarraga@ehu.eus.Phone: +34 \\ 946017033.
}

\begin{abstract}
International experience proves that electricity prices have undergone major changes in volatility since the entry of green technologies. The intermittency of renewable sources is one of the reasons for these changes, as it leads to higher volatility in periods of higher participation by renewables. We argue that the development of the regulatory system promoting renewable electricity also plays a crucial role. We raise a question that deserves attention: could an incentive scheme induce higher share of renewables and lower volatility simultaneously? In this paper, we conduct an empirical analysis with Spanish data. We analyze possible ensuing structural changes in Spanish electricity spot price volatility from January 2002 to December 2017. We identify two structural breaks linked to important measures related to renewable electricity: (i) the abolishment of the feed-in tariff scheme; and (ii) the establishment of a more market-oriented regulation based on investment and operating costs. We conclude that stable regulatory policies reduce volatility even though the presence of renewable sources is greater. Furthermore, market-based policy measures achieve lower volatility, encouraging good integration of intermittent renewable electricity.
\end{abstract}

Keywords: electricity prices, GARCH models, regulation, renewable energy, structural breaks

\section{Introduction}

In the transition to low-carbon economies, incentive-based regulatory policies have been widely used worldwide to promote electricity generation from Renew- 
able Energy Sources (RES-E). ${ }^{1}$ These measures have proven to be successful in expanding renewable capacity, but they have not been exempted from costs. Spain is indeed an interesting case study to evaluate the effect of these regulations, given the high RES-E share rate and the important changes to the regulatory system over the years. Specifically, RES-E presence in Spain has grown steadily since the incentive scheme based on feed-in tariffs (FIT) and feed-in premiums (FIP) ${ }^{2}$ promoting green sources was approved after the liberalization of the electricity market in 1997. However, this system imposed an important cost-burden on consumers (Espinosa and Pizarro-Irizar, 2018) and therefore underwent continuous cost-containment measures from 2010 onwards until it was completely phased out in 2013. Finally, in 2014 it was replaced by a more market-based incentive system based on remuneration for investment and operation of the RES-E plants.

The RES-E share over total production level has also fluctuated, as Figure 1 shows (solid line) throughout this period of continuous regulatory change. The upward RES-E trend to 2010 was linked to the FIT-FIP system, but renewable production share stabilized after the constraints began (though RES-E volatility increased). Figure 1 also shows that RES-E share plays an important role in electricity prices. On the one hand, the comparison of the electricity price series (dashed line) and the evolution of RES-E share on the Spanish electricity market confirms that periods with higher RES-E share result in lower electricity price levels. This is due to the fact that RES-E generally displaces conventional technologies, which usually have higher variable costs due to the use of fossil fuels (Sáenz de Miera et al., 2008). On the other hand, price volatility increases when more intermittent RES-E, such as wind or solar, is produced (Ketterer, 2014, Kyritsis et al., 2017, Rintamaki et al., 2017, Sapio, 2019). Since RES-E production is strongly linked to the regulatory measures concerning its promotion (i.e. incentives driving investment), a RES-E boost via public policies would reduce market prices, but it would also increase price volatility. For Spain, Ballester and Furió (2015) analyze the relationship between RES-E participation and volatility in the Spanish day-ahead electricity market and find a negative relationship between the share of generation attributable to renewables and day-ahead marginal market prices,

\footnotetext{
${ }^{1}$ RES-E includes Wind, Solar Photovoltaic, Solar Thermal, Small Hydro power and Biomass/Wastes. Large Hydro power is not included since remuneration is not different from the Non-RES-E units. Even though Combined Heat and Power (CHP) is not based on renewable sources, we have included it in our study because it is subsidized, given its efficiency potential.

${ }^{2}$ Under a FIT scheme, renewable generators receive a minimum guaranteed price per $\mathrm{kWh}$ sold on the electricity market, including different fees by technology. Under a FIP scheme, renewable generators receive a premium paid on top of the market price for the electricity they sell on the market (Ciarreta et al., 2017a). For a detailed explanation of the FIT-FIP system in Spain see del Río (2008) and references therein.
} 
which is consistent with the findings of the literature at international level. However, when they consider peak and off-peak prices separately they prove that price volatility is higher during peak hours when RES-E participation is lower, whereas volatility decreases when RES-E shares increase. This suggests that changes in volatility could differ depending on the relationship between demand and the level of RES-E participation.

Figure 1: Electricity prices and RES-E share (weekly data)

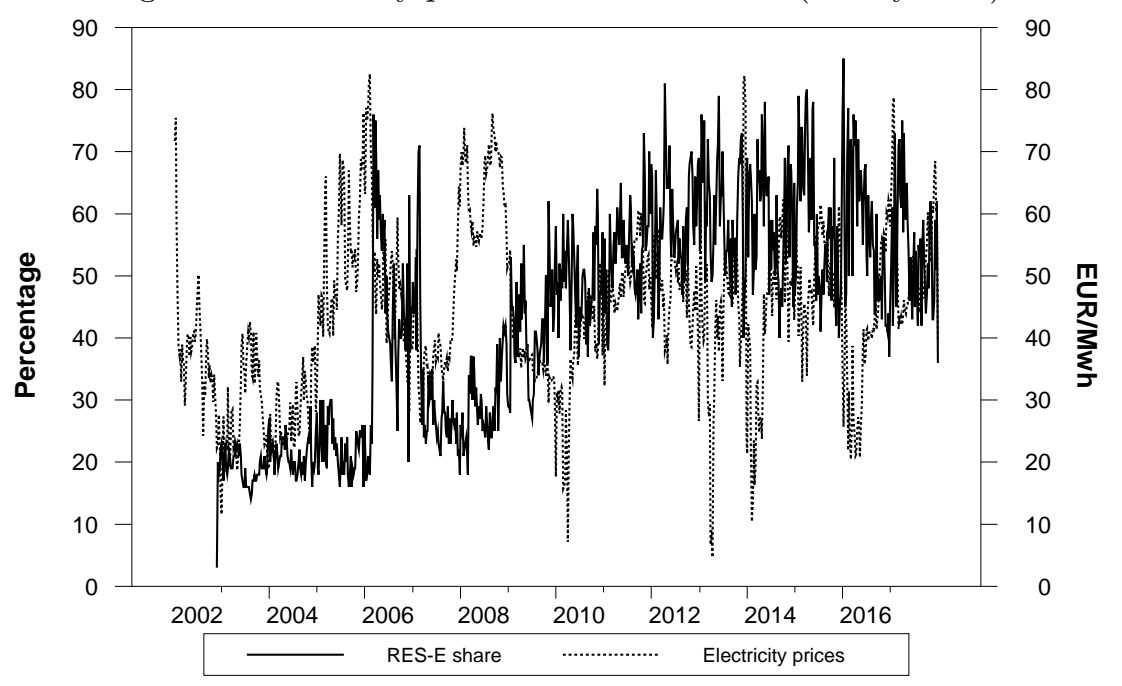

Source: Own work based on price data from the Spanish market operator: OMIE (2018a) for prices and OMIE (2018b) for RES-E.

Electricity markets, compared to other commodities, are particularly volatile, given the lack of substitutes for electricity, fuel price uncertainty, weather effects and the high storage $\operatorname{costs}^{3}$ (Hadsell et al., 2004). Volatility provides a measure of price uncertainty affecting investment negatively. Indeed, it is precisely the degree of price variation, and not the price level itself, which defines a volatile market. When volatility rises, firms may delay investments, since the investment costs increase. Furthermore, investors could even choose less capital-intensive generation technologies, even if this creates higher fuel costs and may further increase the costs of producing electricity (Neuhoff and De Vries, 2004). A low and volatile electricity price could thus delay investment, both in renewable and conventional technologies, limiting the scope of the RES-E promotion scheme itself

\footnotetext{
${ }^{3}$ Electricity storage could foster the large-scale introduction of RES-E, since it would reduce its intermittency. However, this technology is currently available only to a limited extent and at a very high cost.
} 
and also affecting the transformation of the whole electricity system, as shown in Ishii and Yan (2004). Additionally, regulatory uncertainty is another major source of investment risk, particularly in a fast transforming regulatory framework (De Vries and Hakvoort, 2004). The importance of stable regulatory policies is further outlined by Roques et al. (2005) and Cambini and Rondi (2010).

In this sense, we raise a question that deserves attention: what is the role of the RES-E policies implemented in Spain on electricity price volatility? More specifically, do regulatory policies promoting RES-E using FIT and FIP increase volatility more than cost-containing measures such as the new Spanish regulatory system based on a "reasonable rate of return" ?4 And furthermore, could any of these incentive schemes induce lower volatility? A quantitative analysis of the Spanish RES-E policy evolution could help to answer these questions, given that two very different incentive schemes have been in force over time: the FIT-FIP system and the system based on the remuneration for investment in and operating the RES-E plants based on the reasonable return principle.

In this paper, therefore, we analyze possible structural changes ensuing from regulation in the Spanish electricity spot price volatility during the period from January 2002 to December 2017. We focus on RES-E regulation, since most of the regulatory changes in Spain post-liberalization of the electricity sector concern RES-E, given the priority of meeting European climate policy targets in terms of renewable energy consumption and emissions reduction. In particular, we claim that the continuous changes in the Spanish regulatory policy on RES-E could have caused structural breaks in the electricity price volatility. Renewable energy growth in the Spanish electricity market stopped during the period between the abolishment of the FIT-FIP system between 2012 and 2013 and the establishment of the remuneration scheme based on the rate of return of the investments in 2014 . Our hypothesis is that during this period of high regulatory uncertainty, electricity prices experienced important changes in volatility. Moreover, we claim that the volatility of electricity prices could have changed under the different regulatory schemes (FIT-FIP vs. rate of return) and even undergone structural breaks.

This result would have interesting policy implications for countries facing or about to face similar challenges with their incentive systems, since regulators now have to adapt their energy policy towards more market-based support systems, thanks to the technological RES-E developments that prevent the necessity of strong incentive levels such as FIT, and higher RES-E shares. Therefore, selecting the best policy tools for a given market could encourage smoother RES-E integra-

\footnotetext{
${ }^{4}$ The "reasonable return" concept applied in the above-mentioned remuneration regime in Spain is a remuneration supplement for investment paid on top of the market price. It is calculated taking into account a theoretical initial investment value and a regulatory useful life during which the facility is eligible to receive this supplement. See Appendix A for more detail.
} 
tion and thus reduce certain negative effects of price volatility on investment, such as the price risk.

Other authors have also investigated the role of regulatory changes on price volatility in different markets by detecting structural changes. For instance, Fagiani and Hakvoort (2014) analyze whether certificate price volatility in the Swedish / Norwegian market changed after a joint market was created. They conclude that regulatory uncertainty induces a negative impact in terms of increased price volatility. Ewing and Malik (2017) account for the effects of oil price shocks, focusing on the different effect that good and bad news have on oil price volatility dynamics. Mosquera-López and Nursimulu (2019) identify several breaking points along the spot price path on the German electricity market caused by different RES generation periods. With respect to the relationship between RES-E regulation and volatility, Auer (2016) analyzes whether the volatility of electricity prices in Germany has changed significantly with the introduction of RES-E regulation. He finds that German policy measures encourage intermittent renewable electricity to be well integrated in the power system because the price volatility reduced when the marketing mechanism for renewable electricity changed.

Our paper combines the regulatory analysis followed by Fagiani and Hakvoort (2014) with the analysis of the asymmetric effect that different shocks (in our case FIT and the new regulation based on the reasonable rate of return) has on volatility, as suggested by Ewing and Malik (2017). We add to the existing literature by exploring which RES-E policies could lead to a lower price volatility and therefore reduce investment uncertainty on electricity markets. Additionally, this analysis has never been previously performed with electricity data.

The rest of the paper is organized as follows. Section 2 describes and reviews the evolution of the Spanish regulatory system concerning RES-E promotion. Section 3 and Section 4 detail the data and the methodology employed, respectively. Section 5 presents the main empirical results. Section 6 relates the results with the regulatory changes that the Spanish electricity system went through from 2002 to 2017. Finally, Section 7 concludes with some policy implications.

\section{The Spanish regulatory system}

This section begins by summarizing the most relevant regulatory measures implemented on the Spanish electricity market after its liberalization (Subsection 2.1). It is followed by a discussion of the potential implications of different regulatory schemes (Subsection 2.2).

\subsection{Policy overview}

The Electricity Sector Act (BOE, 1997) liberalized the Spanish electricity sector and guaranteed electricity supply at the "lowest possible cost". The legislation, 
which was in force until 2013, established guaranteed of access to the grid for renewable energy producers and specified the first incentive scheme for renewable energy and Combined Heat and Power (CHP). During the greatest renewable expansion period in Spain (from 2004 until 2012), RES-E was therefore supported by a combined system of FIT and FIP, which was established in the Renewable Energy Act (BOE, 2004) and renewed in 2007 (BOE, 2007). During that period, RES-E grew from 9\% gross generation in 2004 to $28 \%$ in 2013 (REE, 2002-2017).

However, one of the most important political concerns at that time was the regulated activities deficits (or tariff deficit), which had increased from $€ 0.25$ billion in the year 2000 to $€ 26$ billion in 2013, and was leading to a significant financial black hole nationwide (CNE/CNMC, 2007-2013). The Spanish tariff deficit was the result of the difference between the income from the electricity system and its regulatory costs. The FIT-FIP incentive scheme to RES-E accounted for a large part of it (€9.3 billion in $2013,46 \%$ of total regulatory costs), which led to an energy reform including the suppression of tariffs in 2013 and the enacted of a new remuneration system for RES-E from 2014 onwards.

The new Electricity Sector Act (BOE, 2013a) derogated the incentive system based on FIT and FIP for both new and existing generation units and established a new more market-oriented remuneration scheme based on a reasonable rate of return of the electricity plants. The new remuneration system for RES-E, in force since mid-2014, supplements market revenues with a specific regulated subsidy, sufficient to attain the minimum level required to recover their investment and operating costs. In the case of technologies with higher operating costs (i.e. Solar Photovoltaic, Solar Thermal and CHP) the regime also provides a supplement aimed at covering the portion of operating costs that cannot be recovered via market prices. See Appendix A for a detailed explanation of this regulatory scheme based on a rate of return.

Table 1 provides a summary of the above mentioned milestones in the Spanish RES-E regulation.

\subsection{Policy analysis}

Regulatory uncertainty is generally associated to excess price volatility compared to periods of stability. Agents can implement more predictable strategies in periods where the regulatory framework remains stable. Prices will therefore fluctuate according to economy fundamentals.

The period between the end of 2012 and mid-2014 was one of intense regulatory instability in Spain, as outlined in Subsection 2.1. The government cut on the FIT-FIP system progressively and, moreover, it announced a new regulatory framework that took several months to set up. During 2013, RES-E generators collected incentives from the former FIT-FIP regime and they had to return these sums over the course of 2014 once the new system was established. Consequently, 
Table 1: Spanish renewable energy policy overview (1997-2016)

\begin{tabular}{|c|c|}
\hline \multirow{4}{*}{$\begin{array}{l}\text { Act } 54 / 1997, \\
\text { RD } 2818 / 1998\end{array}$} & Electricity Sector Act. Liberalization of the electricity sector. \\
\hline & Establishment of a Special Regime (SR) for RES-E and \\
\hline & CHP with an incentive system based on FIT \\
\hline & updated annually and reviewed every four years. \\
\hline \multirow[t]{3}{*}{$\mathrm{RD} 436 / 2004$} & $\begin{array}{l}\text { Renewable Energy Act. Establishment of a methodology based on tariffs } \\
\text { and premiums for the updating and systematization } \\
\text { of the legal and economic regime of }\end{array}$ \\
\hline & $\begin{array}{l}\text { the activity of SR electricity production. This record supersedes } \\
\text { RD 2818/1998. }\end{array}$ \\
\hline & It supposed the true takeoff of RES-E in Spain. \\
\hline \multirow[t]{2}{*}{$\mathrm{RD} 661 / 2007$} & Regulation of the production of electricity under the SR. \\
\hline & $\begin{array}{l}\text { This record supersedes RD } 436 / 2004 \text {. The cost of the regime is borne } \\
\text { by the grid operator, who can pass on costs to consumers. It includes } \\
\text { greater subsidies for biomass and CHP, as well as the introduction } \\
\text { of floors and ceilings for the premium system. }\end{array}$ \\
\hline \multirow{3}{*}{$\begin{array}{l}\text { RD 1614/2010, } \\
\text { RD-1 14/2010 }\end{array}$} & Cuts to the tariff system for solar thermal and wind energy. \\
\hline & $\begin{array}{l}\text { It defines a maximum quota of energy capable of receiving public } \\
\text { support for thermo-solar, photovoltaic and wind energy. }\end{array}$ \\
\hline & $\begin{array}{l}\text { It also establishes a } 0.5 € / \text { MWh fee as a grid access charge, } \\
\text { implemented by RD } 1544 / 2011 \text {. }\end{array}$ \\
\hline RD-1 1/2012 & $\begin{array}{l}\text { Renewable moratorium. Temporary suppression of incentives } \\
\text { (tariffs and premiums) for new energy from renewable sources } \\
\text { and CHP after January, } 2012 \text {. }\end{array}$ \\
\hline Law $15 / 2012$ & Establishment of a $7 \%$ generation charge levied on all generators. \\
\hline \multirow[t]{2}{*}{ RD-1 2/2013 } & Abolishment of the premium system in February, 2013. \\
\hline & Tariffs to existing facilities hold. \\
\hline RD-1 9/2013 & Abolishment of the tariff system in July, 2013. \\
\hline Act $24 / 2013$ & $\begin{array}{l}\text { New Electricity Sector Act from January, 2014. This record } \\
\text { supersedes } 94 / 1997 \text { and it is currently in force. }\end{array}$ \\
\hline RD 413/2014, & New remuneration scheme for RES-E and CHP \\
\hline \multirow[t]{3}{*}{ IET/1045/2014 } & (not called SR anymore). For existing facilities, it is based on a fixed \\
\hline & The moratorium for new facilities is maintained. \\
\hline & This record supersedes RD $661 / 2007$. \\
\hline $\begin{array}{l}\text { RD } 947 / 2015 \\
\text { IET } / 2212 / 2015\end{array}$ & $\begin{array}{l}\text { Regulation of the procedure to assign the remuneration regime } \\
\text { to new RES-E facilities by auction. }\end{array}$ \\
\hline
\end{tabular}

Source: Own work based on official data from the Spanish regulation (BOE 1997, 1998, 2004, 2007, 2010b, 2010c, 2011, 2012a, 2012b, 2013a, 2013b, 2013c, 2014a, 2014b, 2015b, 2015c). 
RES-E generators were on the market without a clear reward scheme for several months, which increased uncertainty in renewable energy promotion and delayed new investment in the sector. Uncertainty was also transmitted to the other generators because many conventional generators were waiting to learn their final positions in the market.

On the contrary, the new incentive scheme in place since 2014 has not been subjected to substantial changes after being introduced and it can therefore be considered a period of stability from a regulatory point of view. However, the system has been subject to intense criticism, since it affected the renewable energy sector by reducing the profitability of many renewable energy facilities (Rojas and Tubío, 2015). Under this new remuneration regime, incentive levels are now revised every six years (in contrast with the FIT-FIP system, in which they were set for 20 years), increasing the levels of returns requested by investors. Additionally, remuneration depends to a greater extent on market prices, increasing the pool price fluctuation risk.

The new incentive scheme pivots around the "reasonable rate of return" concept, given that the aim of the scheme is to balance system income and costs to ensure the sustainability of the electricity system. This reasonable return for RES-E facilities is calculated by adding 300 basic points to the yield on 10-year Spanish sovereign bonds. This value was $7.389 \%$ before taxes when the system was approved. When regulated revenue is not sufficient to cover all system costs, a "coverage coefficient" comes into play, defined as the ratio between regulated system costs and revenues. ${ }^{5}$ The result is that in the short term, RES-E generators will be affected by fluctuations in pool prices, but in the long term they will be less exposed to regulatory risks.

\section{Data and descriptive statistics}

This study uses weekly electricity prices (measured in $€ / M W h$ ) from the Spanish day-ahead market obtained from the Spanish market operator (OMIE, hereinafter $).{ }^{6}$ Prices are constructed as the arithmetic mean of the daily prices of each week for the period from 7 January 2002 to 31 December 2017, resulting in 834 observations.

The use of weekly prices instead of daily prices seems appropriate in this case, given their time-scale flexibility (e.g. four lags mean one month). This is particularly interesting when performing policy evaluation, since the effect of a regulatory

\footnotetext{
${ }^{5}$ Regulated costs affected by this coverage coefficient include supply continuity, capacity payments, renewable incentives, transmission costs and distribution costs, whereas regulated revenues mainly include revenues from access tolls.

${ }^{6}$ For a detailed explanation of the Spanish pool see Ciarreta et al., 2014 and references therein.
} 
announcement would take weeks (or months) in translating into prices. Many studies use weekly (or monthly) data to detect structural breaks to distinguish structural breaks from spikes. For instance, Wang et al. (2015) use monthly data from fisheries to detect structural breaks. Harvey and Lange (2018) use weekly prices on several stock markets to analyze volatility. Finally, Sandberg (2018) use monthly industrial production series in G7 countries to test for unit root when multiple smooth breaks and nonlinear dynamics are present. Regarding electricity markets, Apergis and Lau (2015) use weekly prices to analyze price instability in several Australian electricity markets associated with structural breaks in response to policy events. Valadkhani et al. (2018) use quarterly data on prices in Australian state capitals to detect and analyze spikes in electricity and gas prices. Mishra and Smyth (2014) employ monthly data on natural gas consumption in the United States between April 1974 and September 2013 to show how shocks to natural gas consumption result in temporary deviations from the long-run growth path.

Table 2 shows the main descriptive statistics of the price series. The mean price and standard deviation are $43.87 € / \mathrm{MWh}$ and $13.18 € / \mathrm{MWh}$, respectively. Prices show high volatility along the sample period with values ranging between $4.66 € / \mathrm{MWh}$ and $82.54 € / \mathrm{MWh}$. Furthermore, volatility clusters are observed (see Figure 1), which indicate that Generalized Autoregressive Conditional Heteroscedastic (GARCH) type models might be appropriate to model price volatility. The probability price distribution is symmetric and does not have fat tails. According to the Jarque-Bera test, the price series distribution is normal. Regarding the stationarity of the series, both Augmented Dickey-Fuller (ADF) and Phillips and Perron (PP) unit root tests indicate that the price series is stationary.

Table 2: Descriptive Statistics of prices

\begin{tabular}{lclc}
\hline Minimum & 4.66 & St. Dev. & 13.18 \\
Maximum & 82.54 & Skewness & 0.12 \\
Mean & 43.87 & Kurtosis (exc.) & 0.05 \\
Median & 44.29 & Jarque-Bera & 2.03 \\
ADF & $-4.98^{a}$ & PP & $-6.52^{a}$ \\
\hline
\end{tabular}

Note: $a$ indicates rejection of the null hypothesis of unit root at the $1 \%$ level.

Source: Own work based on price data from the Spanish market operator, OMIE (2018a).

As mentioned above, lower electricity price levels are generally linked to periods with higher RES-E share (see Figure 1), which would imply a negative correlation between them. In order to analyze the pattern of the sample correlation between both series over time, a time-varying correlation coefficient is calculated using a moving window of 16 observations (four months approximately), resulting in a time series of correlation coefficients. Analogously, a time-varying correlation co- 
efficient between RES-E share and price variances, obtained from daily prices, is calculated. Both time series are shown in Figure 2. The series of time-varying coefficients between RES-E share and prices (solid line) shows a negative correlation for most of the sample period, which might be a consequence of the replacement of conventional, more expensive technologies by RES-E. By contrast, a positive correlation between RES-E share and price variances (dashed line) can be observed. The exception observed in the first years of the series is due to the high share of CHP (which is subject to natural gas prices) compared to green technologies until 2007, where the current boost of renewable energy began after the enactment of RD 661/2007. ${ }^{7}$ Note that, as mentioned in Section 1, both RES-E and CHP were eligible to receive subsidies and are therefore included in our analysis.

Figure 2: Time-varying correlation between RES-E share and prices and between RES-E share and variances

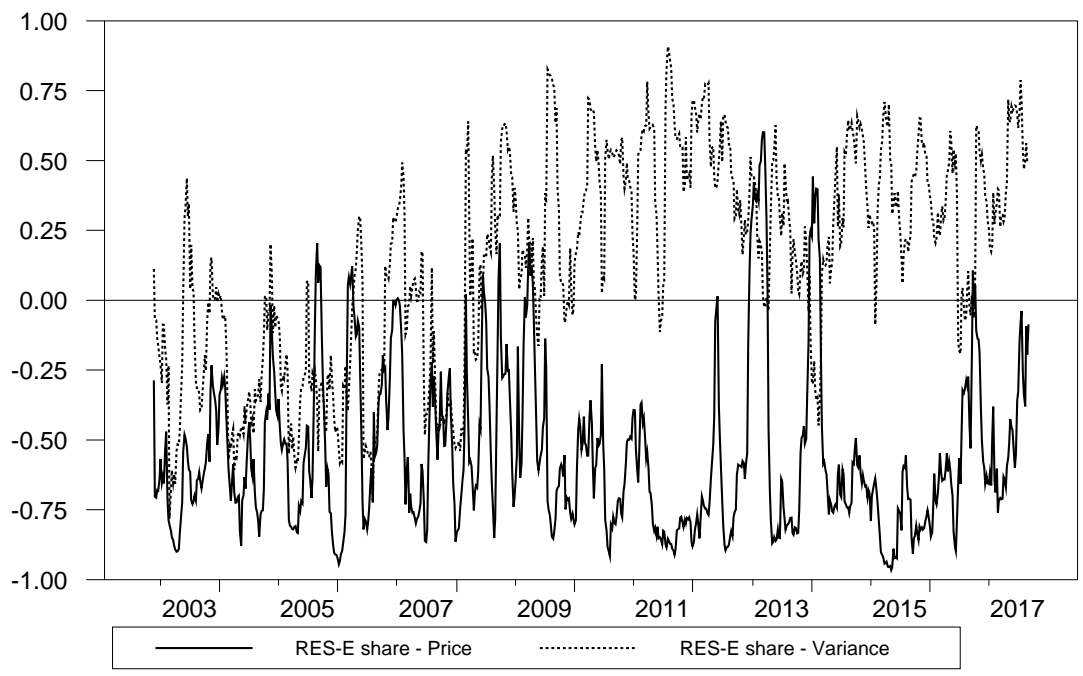

Source: Own work based on price data from the Spanish market operator: OMIE (2018a) for prices and OMIE (2018b) for RES-E.

\section{Methodology}

There is extensive literature using GARCH processes to model time-varying price volatility on electricity markets (see Chan et al., 2008, Higgs, 2009, Liu and

\footnotetext{
${ }^{7} \mathrm{CHP}$ accounted for $55.2 \%$ of total subsidized electricity in 2002 and less than $35 \%$ from 2008 onwards. The figure for 2017 is $29.07 \%$. By contrast, wind power accounted for a share of more than $45 \%$ from 2008 onwards, with figures of $26.15 \%$ in 2002 and $49.42 \%$ in 2017 . Similarly, solar technologies were negligible until 2007 but accounted for $14.17 \%$ (8.65\% for solar photovoltaic and $5.52 \%$ for solar thermal) in 2017. Source: REE (2002-2017).
} 
Shi, 2013, and Ciarreta and Zarraga, 2016, among others).

These models rely on the assumption of constant unconditional variance of prices over time. However, there can be regulatory changes on electricity markets leading to structural breaks and therefore the assumption mentioned does not always hold. In other words, the parameters of the GARCH processes corresponding to the conditional price volatility are affected by structural breaks.

Inclán and Tiao (1994) propose a cumulative sum of squares statistic (IT) to test the null hypothesis of constant unconditional variance against the alternative of one structural break. They also propose an iterative procedure, the so-called Iterated Cumulative Sum of Squares (ICSS) algorithm, to detect multiple breaks in variance, and which is applied to different sample pieces.

However, the main drawback of the test based on the IT statistic is that it assumes that the disturbances are independently and identically distributed, which does not hold for GARCH models. In this case, Sansó et al. (2004) show that the IT statistic is significantly oversized and propose a nonparametric correction of the IT statistic to solve this problem. The resulting statistic is the so-called AIT statistic. ${ }^{8}$ We use the ICSS algorithm based on the AIT statistic to test the null hypothesis of no structural break in the unconditional variance of prices against the alternative of multiple breaks. ${ }^{9}$ The rejection of the null implies that the unconditional variance is not stable over the whole sample period, so models accounting for breaks should be considered in order to obtain reliable estimation and forecast results.

We specify the following equation for the price series:

$$
p_{t}=\gamma_{0}+\sum_{i=1}^{4} \gamma_{i} p_{t-i}+\sum_{i=1}^{11} \delta_{i} M_{i t}+\epsilon_{t},
$$

where $p_{t}$ is the price value at week $t$ and $M_{i}$ are dummy variables for each month of the year from January to November, accounting for possible monthly effects in the price series. The number of lags in prices is selected according to the AIC criterion. We estimate the equation and apply the Ljung-Box statistic to the corresponding residuals and squared residuals to determine whether GARCH processes are justified. ${ }^{10}$ As this is the case, we proceed as follows. First, we apply the ICSS algorithm based on the AIT statistic to the residual series of equation (1) to identify structural breaks. Then, we consider several GARCH-type processes for the residuals, $\epsilon_{t}=\sqrt{h_{t}} u_{t}$, where $h_{t}$ is the conditional variance and $u_{t}$ is a sequence

\footnotetext{
${ }^{8} \mathrm{~A}$ detailed explanation can be found in the original paper.

${ }^{9}$ The test identifies the dates of those breaks.

${ }^{10}$ Results of the tests show that residuals are uncorrelated while their squares are not, indicating that residuals are dependent. Results are available upon request.
} 
of iid normal distributed random variables. Finally, we include the structural breaks in the conditional variance.

Following Ewing and Malik (2017), we consider three different GARCH-type processes. First, the standard $\operatorname{GARCH}(1,1)$ :

$$
h_{t}=w+\alpha \epsilon_{t-1}^{2}+\beta h_{t-1},
$$

where $w>0, \alpha \geq 0, \beta \geq 0$. The volatility persistence is measured by $\alpha+\beta$, which it is required to be strictly less than 1 to ensure that the unconditional variance is finite. The impact of both positive and negative shocks on the conditional variance is the same. However, asymmetric effects are usually observed in electricity markets. Specifically, the so-called inverse leverage effect is often present (see Bowden and Payne, 2008, Liu and Shi, 2013, and Ciarreta and Zarraga, 2016, among others). This effect implies that good news leads to a larger increase in price volatility than bad news. ${ }^{11}$ Therefore, we also consider GARCH-type models accounting for asymmetric effects.

Second, we consider the GJR-GARCH(1,1) model by Glosten et al. (1993):

$$
h_{t}=w+\alpha \epsilon_{t-1}^{2}+\beta h_{t-1}+\theta \epsilon_{t-1}^{2} I_{t-1},
$$

where $I_{t-1}=1$ if $\epsilon_{t-1} \leq 0$ and 0 otherwise. The coefficient $\theta$ captures the asymmetric effects. A negative sign shows that positive shocks produce higher variation than negative ones.

Finally, the asymmetric EGARCH(1,1) model by Nelson (1991):

$$
\log h_{t}=w+\phi_{1} \frac{\left|\epsilon_{t-1}\right|}{\sqrt{h_{t-1}}}+\beta \log h_{t-1}+\phi_{2} \frac{\epsilon_{t-1}}{\sqrt{h_{t-1}}},
$$

where the coefficients are not required to be positive, since even if $\log h_{t}<0$, the volatility will always be positive. The asymmetric response of the volatility due to shocks of different signs is captured by $\phi_{2}$. A positive value of $\phi_{2}$ shows that there is an inverse leverage effect.

The structural breaks are included in the three GARCH processes (Equations 2,3 and 4) by adding the term $\sum_{i=1}^{s} d_{i} S B_{i t}$, where $S B_{i t}$ for $i=1, \cdots, s$ are dummy variables which take the value one from each structural break onwards and zero otherwise, and $s$ is the number of breaks identified. ${ }^{12}$

\footnotetext{
${ }^{11}$ In financial markets the leverage effect is usually observed, which implies that negative shocks affect price volatility more than positive shocks (see Nelson, 1991).

${ }^{12}$ Dummy variables for the structural breaks are also included in the mean equation (1) but they are not significant. That is why they are included in the model only through the GARCH processes.
} 
Equation (1) together with variance equations both ignoring and accounting for structural breaks are estimated by maximum likelihood.

Finally, we calculate several out-of-sample forecast criteria (Mean Absolute Error, MAE, Root Mean Square Error, RMSE, and Mean Absolute Percentage Error, MAPE) ${ }^{13}$ to asses the out-of-sample price forecast performance of the models for the first 26 weeks of the year 2018 (until 1 July). We therefore estimate each model using the sample period until 31 December 2017 and forecast the price for the first week of 2018. Then, we estimate the models recursively adding one new observation each time to obtain the price forecasts until 1 July 2018. The approach of Andersen et al. (2003) is also used to compare the relative forecasting power of different pairs of models.

\section{Results}

We detect two structural breaks using the ICSS algorithm based on the AIT statistic. The first one, in the week starting 26 November 2012 and the second one in the week starting 10 March 2014. Figure 3 shows the price path with the two structural breaks and the corresponding bands at \pm 2 times standard deviation.

We estimate Equation (1) by maximum likelihood considering GARCH errors as in Equations (2), (3) and (4). We then construct the dummy variables $S B_{1}$ and $S B_{2}$ taking value one from each break identified onwards and zero otherwise, and include them in each variance equation to estimate the new equations again. Table 3 reports the estimation results for each GARCH model both ignoring and accounting for structural breaks.

Regarding the estimation results of the mean equation, there are no large differences among the three GARCH processes considered. Prices are explained by their own past, with the price of the last week and that of four weeks ago being significant and positive. Seasonal effects are observed. Estimated prices in January, May, June, July, August and September are significantly higher than in December for all models considered. This result is consistent with the trend of the electricity price series over the year, in which prices are on average higher during most of the summer months. Knittel and Roberts (2005) also observe this effect for the Californian electricity market. In fact, electricity prices contain a strong seasonal component, reflecting heating and cooling needs (see Moral-Carcedo and Vicéns-Otero, 2005 and references herein). In particular, many heating systems use natural gas rather than electricity, whereas air conditioning systems are es-

\footnotetext{
${ }^{13} \mathrm{MAE}=\frac{1}{N} \sum_{t=1}^{N}\left|p_{t}-\hat{p}_{t}\right|, \mathrm{RMSE}=\sqrt{\frac{1}{N} \sum_{t=1}^{N}\left(p_{t}-\hat{p}_{t}\right)^{2}}$, and MAPE $=\frac{1}{N} \sum_{t=1}^{N} \frac{\left|p_{t}-\hat{p}_{t}\right|}{p_{t}}$, where $N$ is the number of forecast observations and $\hat{p}_{t}$ is the predicted value of $p_{t}$ obtained from the models considered.
} 
Figure 3: Weekly prices and structural breaks

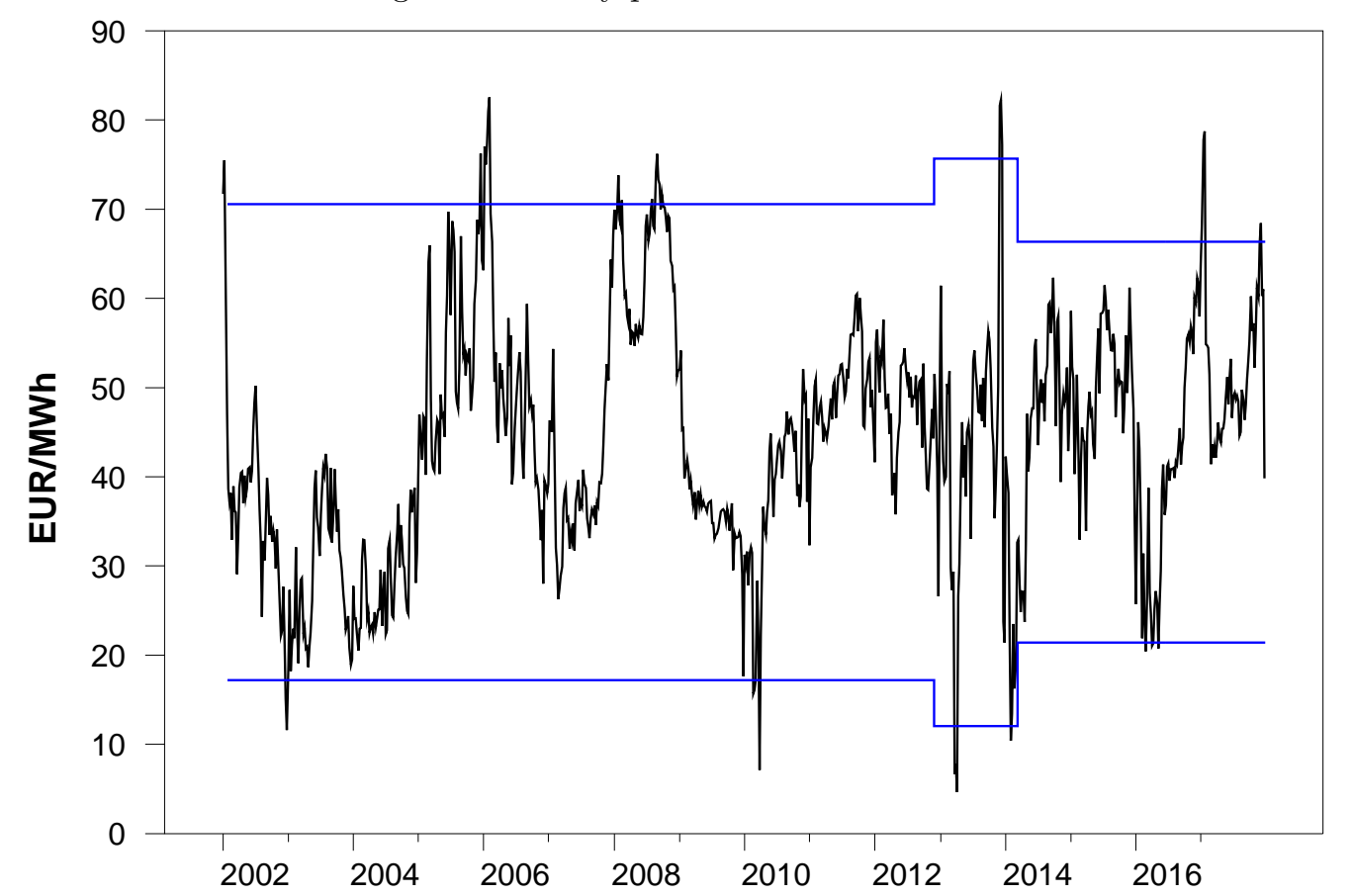

Source: Own work based on price data from the Spanish market operator: OMIE (2018a) for prices. 
sentially electric. This could make electricity prices in summer higher in regions such as Spain or California. Similarly, the low prices found in December can also be explained in terms of the effect of the almost generalized reduction in activity for the Christmas break, since holidays are associated with large declines in electricity demand. Furthermore, other monthly effects are observed, but results differ among the models. A common result is that the magnitude of the estimated coefficients corresponding to the seasonal effects is larger when structural breaks are accounted for in the models. This implies that ignoring structural breaks leads to underestimate the seasonal effects.

Estimation results of the variance equation for each GARCH model show that most coefficients are significant. It should be noted that, in line with other studies (see Arouri et al., 2012, Mensi et al., 2014 and 2015, and Ewing and Malik, 2017, among others) the volatility persistence is overestimated when ignoring structural breaks. ${ }^{14}$ In the standard GARCH model, the estimated volatility persistence $(\hat{\alpha}+\hat{\beta})$ is larger than one and therefore, the unconditional variance is not finite. However, when accounting for structural breaks the estimated volatility persistence decreases to 0.92 . This result is also observed in the rest of the models since there is a decrease in the estimated volatility persistence $(\hat{\alpha}+\hat{\beta}+\hat{\theta} / 2$ for Equation 3 and $\hat{\beta}$ for Equation 4$)$ when accounting for structural breaks.

The coefficients that measure the asymmetric effects of shocks on price volatility are significant. The estimated coefficient $\hat{\theta}$ in the GJR-GARCH model is negative, showing that the estimated impact of positive shocks on volatility ( $\hat{\alpha}=0.42$ and 0.33 when ignoring and accounting for structural breaks, respectively) is larger than that of negative ones $(\hat{\alpha}+\hat{\theta}=0.20$ and 0.16 when ignoring and accounting for structural breaks, respectively). A similar pattern is observed in the estimation results of the EGARCH model since the estimated effect of positive shocks is also greater than that of negative ones. Specifically, positive shocks have an estimated impact of $\hat{\phi}_{1}+\hat{\phi}_{2}=0.59$ and 0.39 when ignoring and accounting for breaks, respectively, whereas the estimated effect of negative shocks is $\hat{\phi}_{1}-\hat{\phi}_{2}=0.39$ when neglecting breaks, and 0.34 when accounting for them. These results show the presence of an inverse leverage effect, usually found on electricity markets and it is associated to the convexity exhibited in the marginal generation costs (Knittel and Roberts, 2005).

Table 3 also shows that structural breaks are significant. The estimated coefficient for the first break $\left(\hat{d}_{1}\right)$ is positive, which indicates larger volatility after the first break. On the contrary, the negative sign of the estimated coefficient for the second break $\left(\hat{d}_{2}\right)$ shows a decrease of volatility after the second break detected.

\footnotetext{
${ }^{14}$ Hillebrand (2005) shows that not accounting for structural changes when estimating a GARCH model leads to an upward biased volatility persistence.
} 
Table 3: Estimation results.

Ignoring structural breaks Including structural breaks GARCH GJR-GARCH EGARCH GARCH GJR-GARCH EGARCH

\begin{tabular}{|c|c|c|c|c|c|c|}
\hline$\hat{\gamma}_{0}$ & 0.15 & -0.17 & -0.53 & -0.11 & -0.33 & -0.51 \\
\hline$\hat{\gamma}_{1}$ & $0.83^{a}$ & $0.82^{a}$ & $0.83^{a}$ & $0.84^{a}$ & $0.83^{a}$ & $0.83^{a}$ \\
\hline$\hat{\gamma}_{2}$ & -0.01 & -0.01 & -0.02 & -0.02 & -0.02 & $-0.01^{a}$ \\
\hline$\hat{\gamma}_{3}$ & 0.04 & 0.06 & $0.08^{c}$ & 0.02 & 0.03 & 0.04 \\
\hline$\hat{\gamma}_{4}$ & $0.10^{a}$ & $0.09^{b}$ & $0.08^{b}$ & $0.12^{a}$ & $0.11^{a}$ & $0.10^{a}$ \\
\hline$\hat{\delta}_{1}$ & $2.47^{a}$ & $3.03^{a}$ & $3.05^{a}$ & $2.76^{a}$ & $3.12^{a}$ & $3.15^{a}$ \\
\hline$\hat{\delta}_{2}$ & -0.28 & 0.24 & -0.12 & 0.23 & 0.55 & 0.19 \\
\hline$\hat{\delta}_{3}$ & 0.43 & 1.13 & $1.21^{c}$ & 0.72 & 1.22 & 1.13 \\
\hline$\hat{\delta}_{4}$ & 1.24 & $1.91^{a}$ & $1.98^{a}$ & $1.52^{c}$ & $2.03^{b}$ & $2.04^{a}$ \\
\hline$\hat{\delta}_{5}$ & $2.70^{a}$ & $3.23^{a}$ & $3.31^{a}$ & $3.06^{a}$ & $3.43^{a}$ & $3.43^{a}$ \\
\hline$\hat{\delta}_{6}$ & $2.18^{a}$ & $2.78^{a}$ & $2.87^{a}$ & $2.59^{a}$ & $3.03^{a}$ & $3.02^{a}$ \\
\hline$\hat{\delta}_{7}$ & $1.68^{b}$ & $2.25^{a}$ & $2.27^{a}$ & $2.04^{b}$ & $2.44^{a}$ & $2.43^{a}$ \\
\hline$\hat{\delta}_{8}$ & $1.70^{b}$ & $2.21^{a}$ & $2.29^{a}$ & $2.05^{a}$ & $2.41^{a}$ & $2.36^{a}$ \\
\hline$\hat{\delta}_{9}$ & $1.77^{b}$ & $2.30^{a}$ & $2.15^{a}$ & $2.16^{a}$ & $2.56^{a}$ & $2.35^{a}$ \\
\hline$\hat{\delta}_{10}$ & 0.75 & $1.15^{c}$ & $1.27^{b}$ & 0.99 & $1.34^{c}$ & $1.36^{c}$ \\
\hline$\hat{\delta}_{11}$ & $1.15^{b}$ & 1.27 & $1.47^{b}$ & $2.26^{a}$ & $2.44^{a}$ & $2.42^{a}$ \\
\hline$\hat{w}$ & $1.48^{a}$ & $1.49^{a}$ & $-0.13^{c}$ & $1.81^{a}$ & $1.79^{a}$ & 0.03 \\
\hline$\hat{\alpha}$ & $0.33^{a}$ & $0.42^{a}$ & & $0.25^{a}$ & $0.33^{a}$ & \\
\hline$\hat{\beta}$ & $0.68^{a}$ & $0.69^{a}$ & $0.92^{a}$ & $0.67^{a}$ & $0.69^{a}$ & $0.87^{a}$ \\
\hline$\hat{\theta}$ & & $-0.22^{a}$ & & & $-0.17^{b}$ & \\
\hline$\hat{\phi}_{1}$ & & & $0.49^{a}$ & & & $0.43^{a}$ \\
\hline$\hat{\phi}_{2}$ & & & $0.10^{a}$ & & & $0.09^{b}$ \\
\hline$\hat{d}_{1}$ & & & & $16.53^{b}$ & $16.07^{a}$ & $0.29^{a}$ \\
\hline$\hat{d}_{2}$ & & & & $-15.75^{b}$ & $-15.67^{a}$ & $-0.27^{a}$ \\
\hline Log-lik. & -2461.03 & -2457.32 & -2450.64 & -2449.12 & -2446.32 & -2439.65 \\
\hline Q stat. & 1.51 & 2.27 & 3.21 & 0.20 & 0.37 & 1.38 \\
\hline$Q^{2}$ stat. & $11.06^{b}$ & $7.77^{c}$ & $10.11^{b}$ & $7.64^{c}$ & $6.38^{c}$ & $7.20^{c}$ \\
\hline
\end{tabular}

$a, b$ and $c$ indicate significance at the $1 \%, 5 \%$ and $10 \%$ levels, respectively.

Q stat. and $Q^{2}$ stat. stand for Ljung-Box statistic for the null hypothesis of no

correlation in the residuals and squared residuals of each model, respectively. 
According to the value of the log-likelihood function, the best model is the EGARCH that accounts for the breaks identified. The last two rows of Table 3 show the results of the Ljung-Box statistic applied to the residuals of each model and their squares. Both residuals and squared residuals can be seen to be uncorrelated at the $5 \%$ significance level for the selected model, which shows the adequacy of the model.

In summary, it should be noted that, on the one hand asymmetric effects should be taken into account when modeling price volatility and, on the other hand, ignoring structural breaks overestimates the asymmetric responses of shocks of different signs. Furthermore, ignoring structural breaks in price modeling upward biases the volatility persistence and underestimates the seasonal effects. This remarks the importance of taking into account structural breaks and asymmetric effects in volatility modeling.

Finally, we use three out-of-sample forecast criteria (MAE, RMSE and MAPE) to assess the price forecast performance of the three GARCH-type models including structural breaks given the importance of accounting for them. The results are consistent with those of in-sample forecast as the EGARCH model is the best to forecast prices for the 26 first weeks of 2018, according to the three criteria. ${ }^{15}$ These results reinforce the importance of taking asymmetric effects into account when modeling and forecasting prices. The approach of Andersen et al. (2003) in the comparison of the forecasting accuracy of the three pairs of GARCH-type models including structural breaks does not give any conclusive result. ${ }^{16}$

\section{Discussion}

According to the structural breaks detected, we identify three different phases in the electricity price series, coinciding with different regulatory periods concerning RES-E support: (i) Phase I: Strong RES-E support (FIT-FIP system), from January 2002 until November 2012; (ii) Phase II: RES-E support halt, from November 2012 to March 2014 together with uncertainty on the content of the new regulatory regime and (iii) Phase III: New RES-E scheme (market-based), from March 2014 to December 2017 (see Table 4).

Differences in the price volatility of the three phases can be related to the evolution of the regulatory system in Spain, which is directly linked with RESE share levels. We argue that the structural breaks we found could be related to RES-E regulation. Specifically, standard deviation of prices during Phase I (increasing presence of RES-E during the FIT-FIP regime) was 13.4. During Phase II, however, the regulatory instability of the abolishment of the FIT-FIP scheme

\footnotetext{
${ }^{15}$ Results are available from the authors upon request.

${ }^{16}$ Results are available upon request.
} 
Table 4: Structural breaks in Spanish electricity spot price volatility

\begin{tabular}{|c|c|c|c|c|}
\hline Phase & Name & Dates & Regulatory system & Std. Dev. \\
\hline I & Strong RES-E support & $01 / 07 / 2002-11 / 25 / 2012$ & FIT-FIP in force & 13.43 \\
\hline II & RES-E support halt & $11 / 26 / 2012-03 / 09 / 2014$ & $\begin{array}{l}\text { FIT-FIP progressive } \\
\text { phase-out }\end{array}$ & 15.74 \\
\hline III & New RES-E scheme & $03 / 10 / 2014-12 / 31 / 2017$ & $\begin{array}{l}\text { Regulatory system based } \\
\text { on return to investment }\end{array}$ & 10.78 \\
\hline
\end{tabular}

resulted in increased price volatility with respect to the previous level (standard deviation grew up to 15.74). Additionally, these cost-containing measures devoted to RES-E policies halted the RES-E expansion trend. Finally, price volatility shrunk even further in Phase III than in Phase I (standard deviation of 10.78) and RES-E started its recovery after a new support scheme more market-oriented came into force, but still did not reach the expansion levels of the FIT scheme.

The relationship between RES-E support schemes and price volatility is a very relevant topic, but at the same time it is very difficult to account for many different changes in regulations and market developments that affect that relationship. In particular, during the study period the electricity market was also affected by two major events apart from renewable-oriented policy measures: (i) other regulatory resolutions; and (ii) changes in installed capacity.

Regarding the first event, there were other important regulatory changes not aimed at RES-E that have not resulted in structural changes. In July 2007, not only was Royal Decree 661/2007 (BOE, 2007) promoting RES-E via a FIT-FIP scheme passed, but the MIBEL market, the integrated market of electricity between Spain and Portugal, was also launched. This larger market was an important step towards the integration of the European single electricity market. In this sense, the Price Coupling of Regions project of European Power Exchanges was launched in 2009 to obtain a single price coupling solution to be used to calculate electricity prices subject to the capacity of the relevant network. However, these important regulatory measures did not result in any significant break in the price time series because it was not followed by a significant increase in the interconnection capacity. Therefore, volatility transmissions across markets were not an issue. In February 2010, another important Spanish regulatory milestone was enacted: the promotion of national coal over imported coal and other conventional technologies (Royal Decree 134/2010, BOE, 2010a). This measure had an important impact on combined cycle technologies, which are marginal technologies together with coal, since they were taken out from the market to be substituted by national coal. However, the absence of structural breaks in the electricity price series in 2010 may be due to the fact that peak demand was met and price spikes did not occur. Finally, Royal Decree 900/2015 (BOE, 2015a), regulating self-consumption and seeking to ensure fair burden-sharing among electricity grid users, did not lead 
to any structural break. This was likely down this new piece of regulation actually preventing large scale entry of self-generators.

Concerning the role of installed capacity in the structural breaks, Ciarreta et al. 2017b show that both RES-E and combined cycle technologies received all new investment in Spain from 2002 onwards. While the installed capacity of nuclear power, hydropower over 50MW and coal plants remained almost constant after 2002, there were important capacity increases for combined cycle units (719\%) and RES-E technologies (225\%) in the period of analysis. Furthermore, after 2007 RES-E and combined cycle technologies can be considered as substitutes in terms of investment, as new investment was transferred from combined cycle, which was no longer growing, to green capacity. However, the development of installed capacity in Spain did not lead to any structural break in the electricity price series.

The intermittent availability of RES-E from sources such as hydro, solar or wind power may also affect electricity prices. Therefore, electricity systems also incorporate a series of intra-day markets and flexible adjustment mechanisms, including ancillary services and capacity payments, which add a significant amount of flexible ramping and capacity products. Considering these adjustment markets in Spain from 2004 to 2017, the weight of the day-ahead market in final electricity prices is found to be always higher than $80 \%$, as Table 5 shows. Moreover, in 2017, after the regulation concerning the participation of renewable sources on balancing mechanisms entered into force, this share reached $88.53 \%$, pushing down the weight of the balancing services in electricity prices even further. Similarly, intra-day markets could also be considered in a volatility analysis. However, when the volumes of energy traded in the day-ahead market and intra-day markets are compared, Table 6 shows that the energy share of the day-ahead market as a proportion of the total energy traded is, again, over 80\% from 2004 to 2017 (and indeed over $85 \%$ for most of the years). Therefore, given the important role of the day-ahead market in both final electricity prices and energy volumes, here we do not take into account other secondary markets and services but rather focus exclusively on day-ahead market data.

Finally, it is also worth noting that we only consider electricity prices in our analysis, despite the volatility that may arise in other markets such as those for conventional fuels (i.e. oil, coal, gas) and carbon pricing. There is empirical evidence in the literature of a correlation between electricity and fuel prices (Furió and Chuliá, 2012) and between electricity and carbon prices (Fabra and Reguant, 2014). This suggests that there could be a price pass-through of fuel and carbon prices in bids by conventional producers, so changes in these markets would already be included in electricity prices. 
Table 5: Weight of the price components on the final electricity price in Spain [\%]. Period 2004-2017.

\begin{tabular}{lccc}
\hline & Day-ahead & Market ancillary services & Capacity payments \\
\hline 2004 & 81.26 & 5.95 & 12.74 \\
2005 & 89.43 & 3.37 & 7.23 \\
2006 & 83.80 & 8.41 & 7.79 \\
2007 & 87.74 & 4.52 & 7.74 \\
2008 & 94.60 & 3.78 & 1.62 \\
2009 & 86.50 & 6.90 & 6.70 \\
2010 & 85.42 & 8.16 & 6.51 \\
2011 & 86.10 & 5.33 & 8.71 \\
2012 & 83.18 & 7.89 & 9.03 \\
2013 & 80.92 & 9.79 & 9.41 \\
2014 & 79.85 & 10.38 & 9.85 \\
2015 & 82.75 & 6.82 & 7.39 \\
2016 & 84.31 & 6.43 & 5.27 \\
2017 & 88.53 & 3.90 & 4.17 \\
\hline
\end{tabular}

Source: Own work based on data from the Spanish market operator (OMIE 2008-2017, OMIE 2019).

Table 6: Weight of the price components on final electricity volumes in Spain [\%]. Period 20042017.

\begin{tabular}{ccc}
\hline & Day-ahead & Intra-day \\
\hline 2004 & 89.00 & 11.00 \\
2005 & 91.60 & 8.40 \\
2006 & 84.77 & 15.23 \\
2007 & 88.26 & 11.74 \\
2008 & 91.18 & 8.82 \\
2009 & 86.89 & 13.11 \\
2010 & 84.54 & 15.46 \\
2011 & 79.95 & 20.05 \\
2012 & 79.19 & 20.81 \\
2013 & 84.26 & 15.74 \\
2014 & 84.82 & 15.18 \\
2015 & 86.14 & 13.86 \\
2016 & 86.71 & 13.29 \\
2017 & 85.87 & 14.13 \\
\hline
\end{tabular}

Source: Own work based on data from the Spanish market operator (OMIE 2008-2017). 


\section{Conclusions}

This paper links structural breaks to regulatory changes promoting RES-E occurred in the Spanish electricity market between 2002 and 2017. We find two structural breaks which imply three phases. According to the price volatility of each phase we can conclude that the existence of regulation uncertainty is related to the period of price instability between 2012 and 2014, which meant greater volatility than in the other two phases. Volatility negatively affects market agents and forces them to implement hedging strategies to protect the value of their assets.

The implementation of a stable renewable remuneration regulatory framework has favored security in the investments. The new regulatory scheme is able to promote RES-E generation at a lower volatility than the previous scheme based on FIT-FIP. This implies that market-based policy measures encourage good integration of intermittent renewable electricity in the Spanish electricity system. Ceteris paribus, it does not necessarily mean that average price has decreased with the new system, but is more stable. In the future, the regulatory framework should be further adapted to balance volatility and increasing shares of RES-E generation.

Our results show how market agents seem to be more concerned with regulation uncertainty than expected regulation changes themselves as agents can react by changing their investment behavior in the latter case. During the 2012-2014 period, the government announced that a new regulatory framework controlling the tariff deficit was necessary. However, it was not finally enacted until 2014 and that prevented agents from optimally deciding on their investment plans. Stable overtime policies encouraging smoother RES-E integration help to reduce negative effects on price risk and excessive volatility.

This result also has interesting policy lessons for countries facing similar challenges with their incentive systems. Regulatory systems based on FIT have been widely explored in the literature, given their widespread presence worldwide; however, our analysis of the new Spanish support mechanism for RES-E based on the reasonable return principle is innovative. Spain is, indeed, an interesting case study for the effect of renewable energy policies, given the high shares of RES-E and the changing characteristics of the regulatory framework over the years. In a world where the transition to low carbon economies is already a reality, this is a very relevant issue.

Finally, our results also suggest that, on the one hand asymmetric effects should be taken into account when modeling price volatility and, on the other hand, ignoring structural breaks overestimates the asymmetric responses of shocks of different signs. It is also worth mentioning that not all regulatory changes yield structural breaks. For instance, the integration of the Spanish and Portuguese electricity markets in 2007 and the Price Coupling of Regions initiative in 2009 
did not lead to any structural break, despite being one of the milestones after the liberalization of the electricity market in the Iberian peninsula. Furthermore, the regulation of self-consumption that entered into force in 2015 and the participation of renewable sources in balancing mechanisms did not lead to any structural break either.

\section{Acknowledgements}

Financial support from Ministerio de Economía y Competitividad and Fondo Europeo de Desarrollo Regional under research grant ECO2015-64467-R (MINECO / FEDER) and from Dpto. de Educación, Universidades e Investigación del Gobierno Vasco under research grant IT1336-19 is acknowledged. Cristina PizarroIrizar also acknowledges financial support from Ministerio de Economía y Competitividad under research grant ECO2015-68023, Ministerio de Ciencia, Innovación y Universidades under research grant RTI2018-093352-B-I00, Gobierno Vasco through the BERC 2018-2021 program and by Ministerio de Economía y Competitividad MINECO through BC3 Maria de Maeztu excellence accreditation MDM-2017-0714. All the authors are grateful for the valuable comments made by participants in the 41st International Conference of the International Association for Energy Economics and the 14th Conference of the Spanish Association for Energy Economics.

\section{Appendices}

\section{Appendix A. The rate of return regulation}

This appendix is based on a previous paper by Ciarreta and Pizarro-Irizar (2014).

Royal Decree 413/2014 regulates the new legal regime and economic activity of electricity production from renewable energy, combined heat and power (CHP), and waste, to which Order IET/1045/2014 is added, in which the remuneration parameters of the facility types are approved. The new regulatory framework for renewable sources, CHP, and waste is thus passed and the remuneration regime established in Act 54/1997 and RD 661/2007 is completely abolished.

The main objective of the new regulatory framework is to guarantee the stability of the electricity system, based on the principle of reasonable "rate of return" on a series of facility types, so that renewable and CHP technologies can cover costs that cannot be recovered in the market without incurring an excessive burden for 
the system. The return on each facility is, therefore, the result of the application of the following formulas during the regulatory lifetime of the facility type:

$$
\begin{aligned}
& R_{f}=R S_{m p}+R_{e}+I_{i n v} \\
& R_{e}=R_{i n v}+R_{o} \\
& R_{i n v}=I C_{f t} \\
& R_{o}=O C_{f t}-M R_{f t}
\end{aligned}
$$

Where $R_{f}$ stands for the return of the facility, $R S_{m p}$ is the return on sales at market price, $R_{e}$ refers to a specific return and $I_{i n v}$ is the incentive to invest in facilities in non-mainland electricity systems that involve overall reductions in generation costs. The $R_{e}$, in turn, depends on the return on investment $\left(R_{i n v}\right)$, which is calculated from the rate of facility investment costs not recovered $\left(I C_{f t}\right)$ and the return on the operation $\left(R_{o}\right)$, obtained as the difference between the operating costs of the facility type $\left(O C_{f t}\right)$ and the market revenue of the facility type $\left(M R_{f t}\right)$.

Additional parameters are as follows:

a) Standard value of the initial investment of the facility type. b) Estimation of the daily and intra-daily market prices. c) Number of hours of operation of the facility type. d) Estimation of future income from production market share. e) Other operating income as defined in Article 24 (for example, possible calls for public aid, waste disposal fees, income from the production of associated useful heat, etc.). f) Estimation of future operating costs. g) Update rate taking the value of "reasonable rate of return". h) Adjustment coefficient of the facility type. i) Net asset value.

The concept of reasonable "rate of return" is established around the average yield of ten-year state bonds (plus a differential) for the 24 months prior to May of the year prior to the start of the regulatory period. For existing facilities, the differential for the first period is 300 basic points on the average performance in the ten-year secondary market prior to the entry into force of RD 413/2014.

This scheme establishes six-year regulatory periods, which in turn are divided into two three-year regulatory half-periods. The first regulatory period ends in 2019, while the first regulatory half-period ends in 2016.

The return parameters may be revisited at the end of each half-period or regulatory period. When the parameters are updated at the end of one regulatory period all the return parameters may be modified, including the value of the "reasonable rate of return". The only parameters that cannot be modified once they are defined are the regulatory useful lifetime and the standard value of the initial investment of a facility type. Additionally, for those technologies whose operating costs depend on fuel prices, parameters are updated yearly.

In the revisions of the regulatory half-periods, two variables are reviewed for the rest of the regulatory period: (i) production market price estimates (adjusted 
to real market prices); and (ii) income from the sale of energy generated (valued at the price of the production market), depending on the trend in market prices and forecasts of operating hours of the facility. The calculation of the return parameters also includes upper and lower limits for the estimation of energy sales. This term is called "value of adjustment for deviations in the market price": it is offset over the useful lifetime of the facility and also generates a positive or negative balance when the average annual price of the daily and intra-daily market is outside these limits.

The number of hours of operation for a specific period is determined by the ratio of energy sold on the market to installed capacity. If the facility has a number of equivalent hours of operation in a year that is lower than the threshold of the corresponding facility type, it could lose the right to the specific return.

Finally, in terms of the useful lifetime of the facility types, 20 years are considered for CHP and wind, 25 years for thermo-solar, mini-hydro, biomass and biogas and 30 years for photovoltaic solar technology. Once the facilities exceed the regulatory useful life, they may remain in operation, but without receiving the remuneration for the investment and the remuneration for the operation. In this case they will only receive payment from the sale of energy in the market.

\section{References}

Andersen, T.G., Bollerslev, T., Diebold, F.X. and Labys, P., 2003. Modeling and forecasting realized volatility. Econometrica, 71(2), 579-625.

Apergis, N. and Lau, M.C.K., 2015. Structural breaks and electricity prices: Further evidence on the role of climate policy uncertainties in the Australian electricity market. Energy Economics, 52, 176-182.

Arouri, M.E.H., Lahiani, A., Lévy, A. and Nguyen, D.K., 2012. Forecasting the conditional volatility of oil spot and futures prices with structural breaks and long memory models. Energy Economics, 34, 283-293.

Auer, B.R., 2016. How does Germany's green energy policy affect electricity market volatility? An application of conditional autoregressive range models. Energy policy, 98, 621-628.

Ballester, C. and Furió, D., 2015. Effects of renewables on the stylized facts of electricity prices. Renewable and Sustainable Energy Reviews, 52, 1596-1609.

BOE, 1997. Act 54/1997 of November 28 (BOE 28.11.1997), N. 285: 3509735126. Available in

https://www.boe.es/boe/dias/1997/11/28/pdfs/A35097-35126.pdf (Spanish).

BOE, 1998. Royal Decree 2818/1998 of December 23 (BOE 30.12.1998), N. 312: 44077-44089. Available in https://www.boe.es/boe/dias/1998/12/30/pdfs/A44077-44089.pdf (Spanish). 
BOE, 2004. Royal Decree 436/2004 of March 12 (BOE 27.03.2004), N. 75: 13217-13238. Available in https://www.boe.es/boe/dias/2004/03/27/pdfs/A13217-13238.pdf (Spanish).

BOE, 2007. Royal Decree 661/2007 of May 25 (BOE 26.05.2007), N. 126: 22846-22886. Available in https://www.boe.es/boe/dias/2007/05/26/pdfs/A22846-22886.pdf (Spanish).

BOE, 2010a. Royal Decree 134/2010 of February 12 (BOE 27.02.2010), N. 51: 19123-19136. Available in https://www.boe.es/buscar/act.php?id=BOE-A-2010-3158 (Spanish).

BOE, 2010b. Royal Decree 1614/2010 of December 7 (BOE 08.12.2010), N. 298: 101853-101859. Available in https://www.boe.es/eli/es/rd/2010/02/12/134 (Spanish).

BOE, 2010c. Royal Decree-act 14/2010 of December 23 (BOE 24.12.2010), N. 312: 106386-106394. Available in https://www.boe.es/boe/dias/2010/12/24/pdfs/BOE-A-2010-19757.pdf (Spanish). BOE, 2011. Royal Decree 1544/2011 of October 31 (BOE 16.11.2011), N. 276: 118002-118009. Available in https://www.boe.es/boe/dias/2011/11/16/pdfs/BOE-A-2011-17891.pdf (Spanish).

BOE, 2012a. Royal Decree-act 1/2012 of January 27 (BOE 28.01.2012), N. 24: 8068-8072. Available in https://www.boe.es/boe/dias/2012/01/28/pdfs/BOE-A-2012-1310.pdf (Spanish). BOE, 2012b. Law 15/2012 of December 27 (BOE 28.12.2012), N. 312: 8808188096. Available in https://www.boe.es/boe/dias/2012/12/28/pdfs/BOE-A-2012-15649.pdf (Spanish).

BOE, 2013a. Act 24/2013 of December 26 (BOE 27.12.2013), N. 310: 105198105294. Available in https://www.boe.es/boe/dias/2013/12/27/pdfs/BOE-A-2013-13645.pdf (Spanish).

BOE, 2013b. Royal Decree-act 2/2013 of February 1 (BOE 02.02.2013), N. 29: 9072-9077. Available in https://www.boe.es/boe/dias/2013/02/02/pdfs/BOE-A-2013-1117.pdf (Spanish).

BOE, 2013c. Royal Decree-act 9/2013 of July 12 (BOE 13.07.2013), N. 167: 52106-52147. Available in https://www.boe.es/boe/dias/2013/07/13/pdfs/BOE-A-2013-7705.pdf (Spanish).

BOE, 2014a. Royal Decree 413/2014 of June 6 (BOE 10.06.2014), N. 140: 43876-43978. Available in https://www.boe.es/boe/dias/2014/06/10/pdfs/BOE-A-2014-6123.pdf (Spanish). BOE, 2014b. Order IET/1045/2014 of June 16 (BOE 20.06.2014), N. 150: 46430-48190. Available in https://www.boe.es/boe/dias/2014/06/20/pdfs/BOE-A-2014-6495.pdf (Spanish).

BOE, 2015a. Royal Decree 900/2015 of October 9 (BOE 10.10.2015), N. 243: 
1-31. Available in

https://www.boe.es/buscar/pdf/2015/BOE-A-2015-10927-consolidado.pdf (Spanish).

BOE, 2015b. Royal Decree 947/2015 of October 16 (BOE 17.10.2015), N. 249: 97340-97342. Available in https://www.boe.es/boe/dias/2015/10/17/pdfs/BOE-A-2015-11200.pdf (Spanish).

BOE, 2015c. Order IET/2212/2015 of October 23 (BOE 24.10.2015), N. 255: 100337-100350. Available in https://www.boe.es/boe/dias/2015/10/24/pdfs/BOE-A-2015-11432.pdf (Spanish).

Bowden, N. and Payne, J.E., 2008. Short term forecasting of electricity prices for MISO hubs: Evidence from ARIMA-EGARCH models. Energy Economics, 30, 3186-3197.

Cambini, C. and Rondi, L., 2010. Incentive Regulation and investment: evidence from European energy utilities. Journal of Regulatory Economics, 38(1), $1-26$.

Chan, K.F., Gray, P. and van Campen, B., 2008. A new approach to characterizing and forecasting electricity price volatility. International Journal of Forecasting, 24, 728-743.

Ciarreta, A., Espinosa, M.P. and Pizarro-Irizar, C., 2014. Is green energy expensive? An empirical evidence from the Spanish electricity market. Energy Policy, 69, 205-215.

Ciarreta, A., Espinosa, M.P. and Pizarro-Irizar, C., 2017a. Optimal regulation of renewable energy: A comparison of Feed-in Tariffs and Tradable Green Certificates in the Spanish electricity system. Energy Economics, 67, 387-399.

Ciarreta, A., Espinosa, M.P. and Pizarro-Irizar, C., 2017b. Has renewable energy induced competitive behavior in the Spanish electricity market? Energy Policy, 104, 171-182.

Ciarreta, A. and Pizarro-Irizar, C., 2014. La nueva reforma del mercado eléctrico español: eficiencia y austeridad. Cuadernos Económicos de ICE, 88, 97-126.

Ciarreta, A. and Zarraga, A., 2016. Modeling realized volatility on the Spanish intra-day electricity market. Energy Economics, 58, 152-163.

CNE/CNMC, (2007-2013). National Energy Commission/National Commission of Markets and Competence (CNE/CNMC). Liquidaciones de actividades reguladas del sector eléctrico. Available in

https://www.cnmc.es/eses/ energ\%C3\%ADa/energ\%C3\%ADael\%C3\%A9ctrica/retribu ci\%C3\%B3nespec\%C3\%ADficayliquidacion es.aspx?p=p3\&ti=Liquidaciones\%20sector\% 20el\%C3\%A9ctrico (Spanish).

De Vries, L.J. and Hakvoort, R.A., 2004. The Question of Generation Adequacy in Liberalised Electricity Markets. FEEM Working Paper No. 120.04 
(September 2004).

del Río, P., 2008. Ten years of renewable electricity policies in Spain: An analysis of successive feed-in tariff reforms. Energy Policy, 36, 2917-2929.

Espinosa, M.P. and Pizarro-Irizar, C., 2018. Is renewable energy a cost-effective mitigation resource? An application to the Spanish electricity market. Renewable and Sustainable Energy Reviews, 94, 902-914.

Ewing, B.T. and Malik, F., 2017. Modelling asymmetric volatility in oil prices under structural breaks. Energy Economics, 63, 227-233.

Fabra, N. and Reguant, M., 2014. Pass-Through of emissions costs in electricity markets. American Economic Review, 104(9), 2872-2899.

Fagiani, R. and Hakvoort, R., 2014. The role of regulatory uncertainty in certificate markets: A case study of the Swedish/Norwegian market. Energy Policy, 65, 608-618.

Furió, D. and Chuliá, H., 2012. Price and volatility dynamics between electricity and fuel costs: some evidence for Spain. Energy Economics, 34, 2058-2065.

Glosten, L.R., Jagannathan, R. and Runkle, D.E., 1993. On the relation between the expected value and the volatility of the nominal excess return on stocks. Journal of Finance, 48, 1779-1801.

Hadsell, L., Marathe, A. and Shawky, H.A., 2004. Estimating the volatility of wholesale electricity spot prices in the US. The Energy Journal, 25(4), 23-40.

Harvey, A. and Lange, R-J., 2018. Modeling the interactions between volatility and returns using EGARCH-M. Journal of Time Series Analysis, 39, 909-919.

Higgs, H., 2009. Modelling price and volatility inter-relationships in the Australian wholesale spot electricity markets. Energy Economics, 31, 748-756.

Hillebrand, E., 2005. Neglecting parameter changes in GARCH models. Journal of Econometrics, 129, 121-138.

Inclán, C. and Tiao, G.C., 1994. Use of cumulative sums of squares for retrospective detection of changes of variance. Journal of the American Statistical Association, 89, 913-923.

Ishii, J. and Yan, J., 2004. Investment under regulatory uncertainty: US electricity generation investment since 1996. CSEM Working Paper 127, Center for the Study of Energy Markets, University of California Energy Institute, Berkeley.

Ketterer, J., 2014. The impact of wind power generation on the electricity price in Germany. Energy Economics, 44, 270-280.

Knittel, C.R. and Roberts, M.R., 2005. An empirical examination of restructured electricity prices. Energy Economics, 27, 791-817.

Kyritsis, E., Andersson, J. and Serletis, A., 2017. Electricity prices, large-scale renewable integration, and policy implications. Energy Policy, 101, 550-560.

Liu, H. and Shi, J., 2013. Applying ARMA-GARCH approaches to forecasting short-term electricity prices. Energy Economics, 37, 152-166. 
Mensi, W., Hammoudeh, S. and Yoon, S.M., 2014. How do OPEC news and structural breaks impact returns and volatility in crude oil markets? Further evidence from a long memory process. Energy Economics, 42, 343-354.

Mensi, W., Hammoudeh, S. and Yoon, S.M., 2015. Structural breaks, dynamic correlations, asymmetric volatility transmission, and hedging strategies for petroleum prices and USD exchange rate. Energy Economics, 48, 46-60.

Mishra, V. and Smyth, R., 2014. Is monthly US natural gas consumption stationary? New evidence from a GARCH unit root test with structural breaks. Energy Policy, 69, 258-262.

Moral-Carcedo, J. and Vicéns-Otero, J., 2005. Modelling the non-linear response of Spanish electricity demand to temperature variations. Energy Economics, 27(3), 477-494.

Mosquera-López, S. and Nursimulu, A., 2019. Drivers of electricity price dynamics: Comparative analysis of spot and futures markets. Energy Policy, 126, 76-87.

Nelson, D.B., 1991. Conditional heteroskedasticity in asset returns: a new approach. Econometrica, 59, 347-370.

Neuhoff, K. and De Vries, L., 2004. Insufficient incentives for investment in electricity generations. Utilities Policy, 12(4), 253-267.

OMIE, 2008-2017. Annual reports 2008-2017.

OMIE, 2018a. Hourly prices Spanish day-ahead market

(marginalpdbc_YYYYMMDD.txt).

http://www.omie.es/aplicaciones/datosftp/datosftp.jsp?path=/marginalpdbc/

Accessed: 2018-12-05

OMIE, 2018b. Hourly quantity Spanish day-ahead market by technology (pdbc_stota_YYYYMMDD.txt).

http://www.omie.es/aplicaciones/datosftp/datosftp.jsp?path=/pdbc_stota/

Accessed: 2018-12-05

OMIE, 2019. Market results. Components of the average final price of the day-ahead market.

http://www.omie.es/files/flash/ResultadosMercado.html\#

Accessed: 2019-11-06

REE, 2002-2017. Red Eléctrica de España (REE). El Sistema eléctrico español. Annual report. Available in http://www.ree.es/es/publicaciones (Spanish).

Rintamaki, T., Siddiqui, A.S. and Salo, A., 2017. Does renewable energy generation decrease the volatility of electricity prices? An analysis of Denmark and Germany. Energy Economics, 62, 270-282.

Rojas, A. and Tubío, B., 2015. Spain's renewable energy regime: Challenges and uncertainties. Spanish Economic and Financial Outlook, 4(2), 57-66.

Roques, F.A., Newberry, D.M. and Nuttall, W.J., 2005. Investment Incen- 
tives and Electricity Market Design: the British Experience. Review of Network Economics, 4(2), 93-128.

Sandberg, R., 2018. Unit Root Testing in Multiple Smooth Break Models with Nonlinear Dynamics. Journal of Time Series Analysis, 39, 942-952.

Sáenz de Miera, G., del Río, P. and Vizcaíno, I, 2008. Analyzing the impact of renewable electricity support schemes on power prices: The case of wind electricity in Spain. Energy Policy, 36(9), 3345-3359.

Sansó, A., Aragó, V. and Carrion-i-Silvestre, J.L., 2004. Testing for changes in the unconditional variance of financial time series. Revista de Economía Financiera, 4, 32-53.

Sapio, A., 2019. Greener, more integrated, and less volatile? A quantile regression analysis of Italian wholesale electricity prices. Energy Policy, 126, 452-469.

Valadkhani, A., Nguyen, J. and Smyth, R., 2018. Consumer electricity and gas prices across Australian capital cities: Structural breaks, effects of policy reforms and interstate differences. Energy Economics, 72, 365-375.

Wang, B., Sun, J. and Motter, A.E., 2015. Detecting structural breaks in seasonal time series by regularized optimization. https://arxiv.org/pdf/1505.04305. 